\title{
Journal of Experimental \& Clinical

\section{Follicular dendritic cell sarcoma of the neck: Report of a case treated by surgical excision and COP plus (PEG)-liposomal} doxorubicin

\author{
Francesco Pisani*1, Mirella Marino ${ }^{2}$, Steno Sentinelli² ${ }^{2}$ and \\ Maria Concetta Petti ${ }^{1}$
}

Address: ${ }^{1}$ Department of Hematology, Regina Elena National Cancer Institute, Rome, Italy and ${ }^{2}$ Department of Phatology, Regina Elena National Cancer Institute, Rome, Italy

Email: Francesco Pisani* - fr.pisani@tiscali.it; Mirella Marino - mirellamarino@inwind.it; Steno Sentinelli - steno8@virgilio.it; Maria Concetta Petti - mcpetti@ifo.it

* Corresponding author

Published: 2 September 2008

Journal of Experimental \& Clinical Cancer Research 2008, 27:33 doi:10.1 186/1756-9966-27-33

This article is available from: http://www.jeccr.com/content/27/I/33

(c) 2008 Pisani et al; licensee BioMed Central Ltd.

This is an Open Access article distributed under the terms of the Creative Commons Attribution License (http://creativecommons.org/licenses/by/2.0), which permits unrestricted use, distribution, and reproduction in any medium, provided the original work is properly cited.
Received: 12 June 2008

Accepted: 2 September 2008

\begin{abstract}
Background: Follicular dendritic cell (FDC) sarcoma is a rare neoplasm arising in lymph nodes but also in extranodal sites from accessory cells of the immune system that are essential for the function of antigen presentation and germinal center reaction regulation. FDC sarcoma has a significant recurrent and metastatic potential and for these reason it should be viewed as an intermediate grade malignancy.
\end{abstract}

Methods: We report the case of a 49-year old woman patient who showed persistent, enlarged, hard, cervical lymph node. The most common histologic feature was the presence of oval to spindle cells with elongated nuclei, vesicular or stippled chromatin and scant eosinophilic cytoplasm. Immunohistochemically, tumor cells were diffusely positive for follicular dendritic cell markers CD2I, CD23 and negative for cytokeratin.

The patient after complete excision of the lymph node underwent five courses of adjuvant chemotherapy with COP plus PEG-liposomal doxorubicin, considering the propensity of the tumor to metastasize.

Results: No hematological or cardiac toxicity were registered and among the other extra hematological effects only transitory palmar erythrodysesthesia is worthy of mention. After a follow up of 5 years the patient is alive and in CR.

Conclusion: These results suggest that this therapeutic modality may be useful in the management of FDC sarcoma.

\section{Background}

Follicular dendritic cell sarcoma is a rare tumor arising from antigen-presenting cells of the B-cell follicles of nodal and extranodal sites; these cells are important for germinal center reaction regulation. It was first described in 1986 by Monda et al [1] and in recent years there has 
been an increasing interest in this neoplasm due to availability of specific antibodies to confirm FDC lineage and thus wider recognition.

Almost all patients have been adults, with a median age of 40 years and with a slight female predominance [2]. Most patients present with cervical or axillary lymphoadenopathy but extranodal sites, including oral cavity, tonsil, gastrointestinal tract, soft tissue [3] and breast, may occur in almost one third of the patients.

We report a case of nodal FDC sarcoma who was successfully diagnosed and treated with surgery and chemotherapy, comprehending PEG-liposomal doxorubicin.

\section{Methods}

A 49 year old woman presented at our Institute with an enlarged $(2 \mathrm{~cm})$, hard, mobile lymph node of the right cervical area that had been present for about 3 months.

An ultrasound examination of the thyroid gland showed two nodules of $12 \times 8 \mathrm{~mm}$ and $6 \times 6 \mathrm{~mm}$ and a fine needle aspiration cytology was benign. The patient underwent a right neck dissection with complete excision of lymph node and multiple biopsies of nasopharynx, pyriform sinus and postcricoid area.

The fiberlaryngoscopic and oralpharyngealscopic evaluations were negative for extensive or focal malignancies.

\section{Histopathologic findings}

The $2 \mathrm{~cm}$ lymph node was partially substituted from a proliferation of oval-to-spindle cells with vesicular or stippled chromatin and oval to spindle shaped nuclei. The cells had scant eosinophilic cytoplasm with indistinct border and the mitotic rate was low (Figure 1).

The follicular areas of lymph node were disappeared but residual $\mathrm{T}$ lymphoid tissue was generally present. Immunologically, the tumor cells showed a close resemblance to the normal follicular dendritic cells with consistent expression of CD21 [C3d complement receptor] (Figure 2 ) and CD23 (Figure 3). Tumor cells were negative for cytokeratin, CD45, CD20, CD3, CD30, CD68, CD35 and CD1a; Ki-67 was positive in about $15 \%$ of the cells. The final diagnosis was a follicular dendritic cell sarcoma. Other tissue specimens from nasopharynx, pyriform sinus and postcricoid area were free from malignant involvement.

\section{Clinical data}

Routine hematological parameters showed hemoglobin $13.1 \mathrm{~g} / \mathrm{dl}$, WBC $5.9 \times 10^{9} / \mathrm{l}$ (53\% polymorphonuclear cells, 39\% lymphocytes, $8 \%$ monocytes), platelets $214 \times$ $10^{9} / 1$, all the other biochemical parameters were normal.

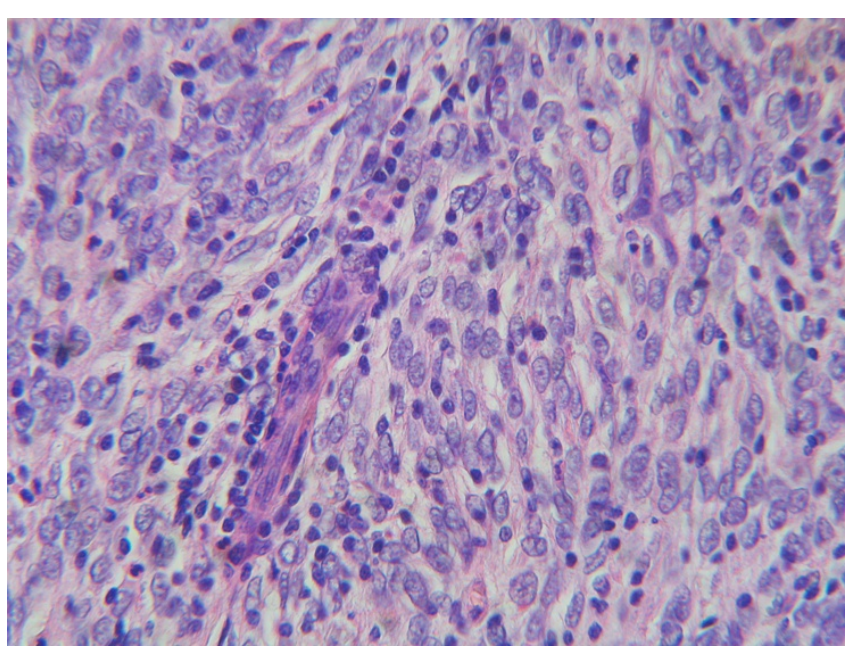

Figure I

Partial substitution of lymph node from a proliferation of oval-to-spindle cells with vesicular or stippled chromatin, elongated nuclei, scant eosinophilic cytoplasm and with low mitotic rate. H\&E, $\times 400$.

Hepatitis B and C, HIV serology were negative, EBV serology showed no IgM antibodies but positivity for IgG anti VCA and IgG anti EBNA.

Bone marrow aspiration and trephine yielded a normal hemopoiesis. A total body computed scan was made showing multiple hepatic angiomas (confirmed by MRI scan) and small subpleural fibrocalcific residuals, the rest of the exploration was normal. The patient also underwent an echocardiography that disclosed a good cardiac function with normal ejection fraction.

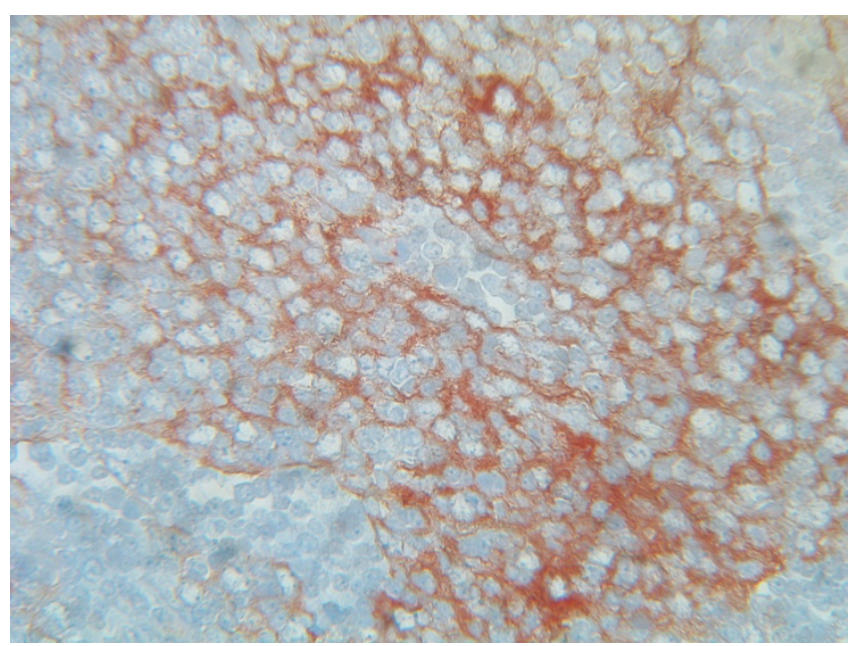

Figure 2

Immunohistochemical staining: Positive staining for CD 21 
Postoperative adjuvant chemotherapy was administered; the patient received five courses of COP+PEG-liposomal doxorubicin according to the following schedule: Cyclophosphamide $750 \mathrm{mg} / \mathrm{m}^{2}$ i.v. (day 1), Vincristine $1.4 \mathrm{mg} /$ $\mathrm{m}^{2}$ (day 1), PEG-liposomal doxorubicin (Caelyx) $40 \mathrm{mg} /$ $\mathrm{m}^{2}$ i.v (day 1) and Prednisone $100 \mathrm{mg}$ po days $1-5$, every 3 weeks.

\section{Results}

No hematological toxicity was reported, but WHO grade 3 skin toxicity was observed. In particular the patient after the fourth cycle developped a palmar erytrodysesthesia with painful erytema that was attributed to PEG-liposomal doxorubicin and consequently we reduced at $70 \%$ the dose of Caelyx in the last course of treatment. The erytrodysesthesia was transitory and successful treated with mild dose of prednisone per os.

A total body CT scan performed one month after the last course of chemotherapy was negative for lymphoadenophaty (Figure 4) and previous subpleural fibrosis was not modified. Three months after chemotherapy, the patient also underwent total body 18-F-FDG PET/CT that showed no residual tumor activity (Figure 5). The patient is disease free at 5 years after the diagnosis with CT scan negative.

\section{Discussion}

Follicular dendritic cell sarcoma is a rare neoplasm that can involve lymph nodes or extranodal sites $[2,4,5]$. Once FDC sarcoma is suspected from the histologic findings, immunohistochemical stains for follicular cell differentiation must be performed to avoid the potential for misdiagnosis. CD21 and CD35, directed respectively against the $\mathrm{C} 3 \mathrm{~d}$ and C3b receptors, together with CD23 and clusterin

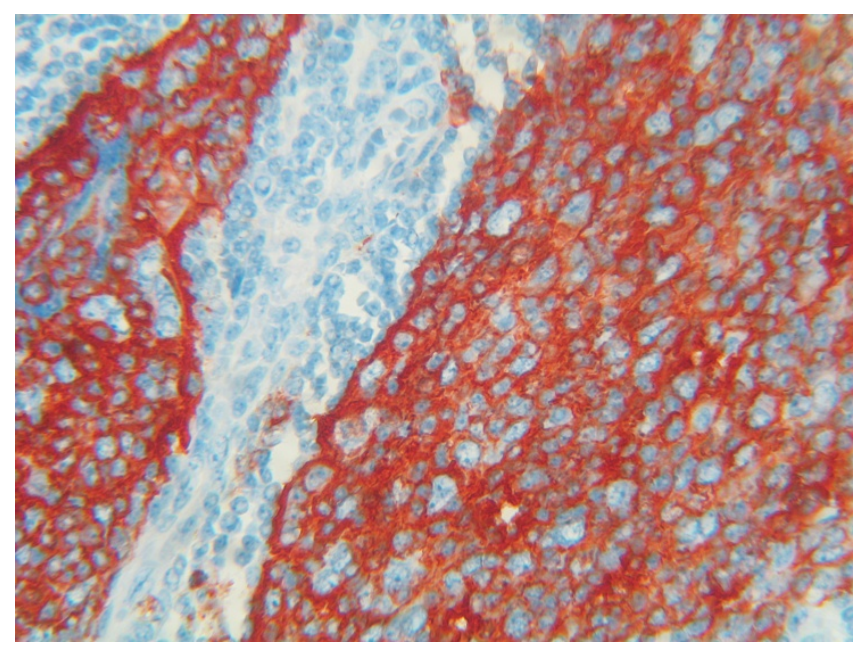

Figure 3

Positive staining for CD23

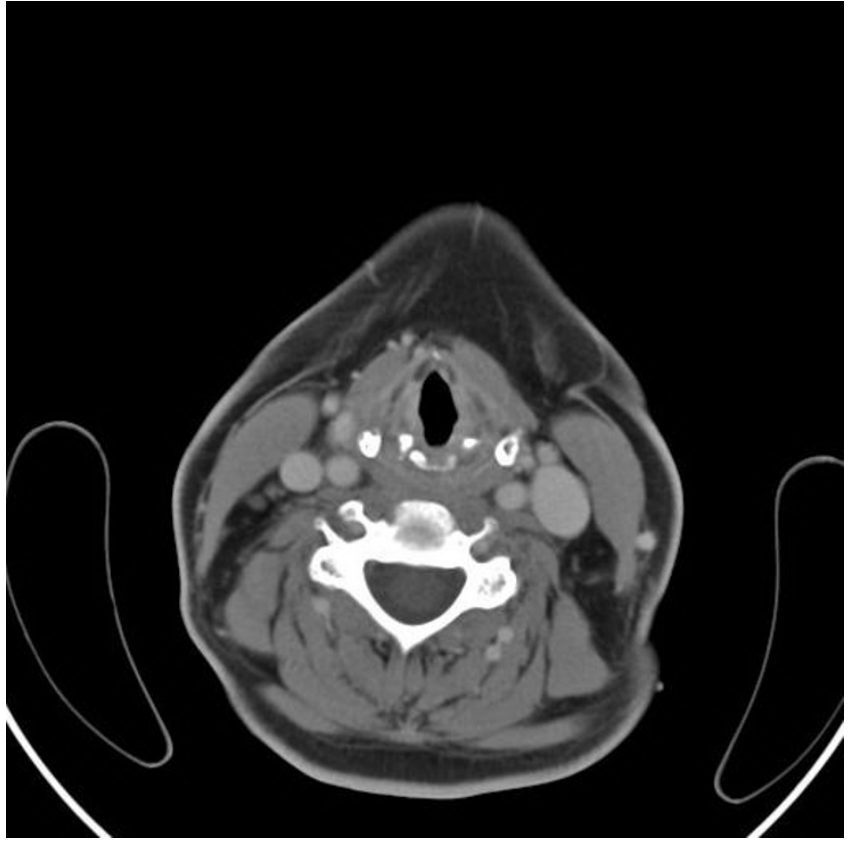

Figure 4

Cervical region $C T$ scan, one month after chemotherapy, negative for residual mass

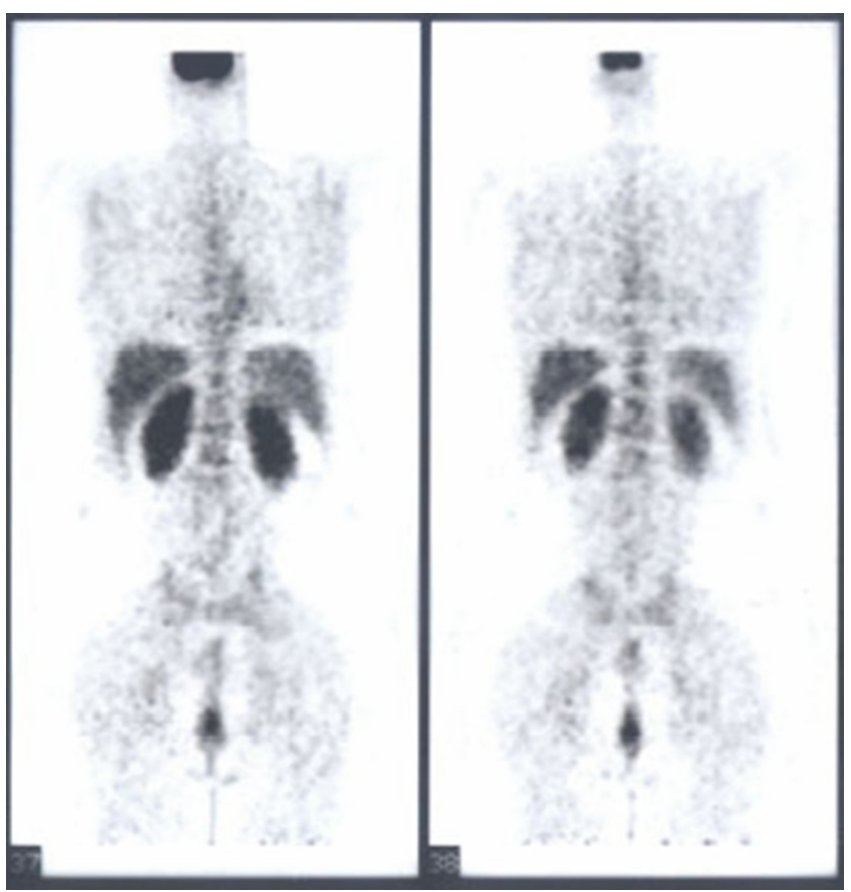

Figure 5

Total body I8-FDG PET three months after chemotherapy, showing no residual tumor activity 
are the most widely used markers, demonstrating follicular dendritic cells differentiation and should help in their recognition $[2,6-9]$.

FDC sarcoma was considered an indolent tumor with low tendency of recurrence or metastasis; but recent larger reports with longer follow up have showed that FDC sarcoma is more aggressive tumor and should be considered an intermediate-grade malignancy. Chan et al. have reported that at least $40 \%$ of documented FDC sarcomas have recurred and $25 \%$ have metastasized with a mortality rate of $16.7 \%[2,10]$.

Because this significant recurrent and metastatic potential it is reasonable that resected localized disease may be prevented from recurrence by adjuvant radiotherapy or chemotherapy [11-13].

In our case report, the patient underwent surgical excision and postoperatively was given five cycles of COP plus Caelyx, utilizing cyclophosphamide, vincritine, prednisone and pegylated liposomal doxorubicin.

PEG liposomal doxorubicin is an alternative preparation of doxorubicin, which has been shown to have reduced cardiotoxicity and is characterized by a very long circulation half-life, favorable pharmacokinetic behaviour and specific accumulation tumor tissues $[14,15]$. PEG liposomal doxorubicin has already shown activity in soft-tissue sarcoma, head and neck cancer, multiple myeloma, aggressive non-Hodgkin's lymphoma.

Based on these encouraging experiences and in consideration of the higher response rate, shorter time to response and less toxicity obtained with PEG liposomal doxorubicin also in the treatment of AIDS-related Kaposi's sarcoma [16], compared with conventional doxorubicin, we decided to treat our patient with COP plus Caelyx regimen, even if she had no particular cardiac risk. No hematological or cardiac toxicity was registered and among the other extra hematological effects only palmar erythrodysesthesia was worthy of mention. The patient is alive and event free at 5 years after diagnosis.

In the literature treatment modality of FDC sarcoma varied widely although surgical resection was often included. With a median follow up of 18 months, about $40 \%$ of the cases recurred and the 5 years recurrence-free survival was $27.4 \%$, further the role of chemotherapy and radiotherapy in the treatment of this neoplasm is not yet clearly defined $[2,10]$. Clinical findings, histology and immunophenotype of our case appear to be typical of FDC sarcoma but the complete resection achieved by surgery and the use of adjuvant COP plus PEG liposomal doxorubicin, regimen ever reported to our knowledge to treat this tumor, and the very good response at 5 years of follow-up show some issues of interest.

A longer follow-up and further studies are warranted to determine whether this combination treatment may be useful in the management of FDC sarcoma, at least in localized nodal disease, once it is identified and well characterized by the appropriate application of immunohistochemical staining.

\section{References}

I. Monda L, Warnke R, Rosai J: A primary lymph node malignancy with features suggestive of dendritic reticulum cell differentiation. A report of 4 cases. Am J Pathol 1986, 122:562-72.

2. Shia J, Chen W, Tang LH, Carlson DL, Qin J, Guillem MJ, Nobrega J, Wong WD, Klimstra DS: Extranodal follicular dendritic cell sarcoma: clinical, pathologic, and histogenetic characteristics of an underrecognized disease entity. Virchows Arch 2006, 449: $148-158$.

3. Schwarz RE, Chu P, Arber DA: Extranodal follicular dendritic cell tumor of the abdominal wall. J Clin Oncol 1999, I 7:2290-2292.

4. Perez-Ordonez B, Rosai J: Follicular dendritic cell tumor: Review of the entity. Semin Diagn Pathol I998, I 5: I 44-I 54.

5. Biddle DA, Ro JY, Yoon GS, Yong YW, Ayala AG, Ordonez NG: Extranodal follicular dendritic cell sarcoma of the head and neck region: three new cases, with a review of the literature. Mod Pathol 2002, I 5:50-8.

6. Chan AC, Chan KW, Chan JKC, Au WY, Ho WK, Ng WM: Development of follicular dendritic cell sarcoma in hyaline-vascular Castleman's disease of the nasophariynx: tracing its evaluation by sequential biopsies. Histopathology 200I, 38:5I0-5I8.

7. Pileri SA, Grogan TM, Harris NL, Banks P, Campo E, Chan JKC, Faver RD, Delsol G, De wolf-Peeters C, Falini B, Gascoyne RD, Gaulard P, Gatter KC, Isaacson PG, Jaffe ES, Kluin P, Knowles DM, Mason DY, Mori S, Muller-Hermelink HK, Piris MA, Ralfkiaer E, Stein H, Su IJ, Warnke RA, Weiss LM: Tumours of hystiocytes and accessory dendritic cells: an immunohistochemical approach to classification from the International Lymphoma Study Group based on 61 cases. Histopathology 2002, 4I:I-29.

8. Khalid S, Yaqoob N, Pervez S: Follicular dendritic cell sarcoma of lymph node - a rare entity. J Pak Med Assoc 2006, 56: I37-I 39.

9. Yakushijin Y, Shikata H, Kito K, Ohshima K, Kojima K, Hato T, Hasegawa $H$, Yasukawa M: Follicular dendritic cell tumor as an unknown primary tumor. Int J Clin Oncol 2007, 12:56-58.

10. Chan JKC, Fletcher CD, Nayler SJ, Cooper K: Follicular dendritic cell sarcoma. Clinicopathologic analysis of 17 cases suggesting a malignant potential higher than currently recognized. Cancer 1997, 179:294-313.

II. Fonseca R, Yamakawa M, Nakamura S, van Heerde P, Miettinen M, Shek TW, Myhre Jensen O, Rousselet MC, Tefferi A: Follicular dendritic cell sarcoma and interdigitating reticulum cell sarcoma: a review. Am J Hematol 1998, 59:161-167.

12. Nakashima T, Kuratomi Y, Shiratsuchi H, Yamamoto H, Yasumatsu R, Yamamoto T, Komiyama S: Follicular dendritic cell sarcoma of the neck; a case report and literature review. Auris Nasus Larynx 2002, 29:40I-403.

13. Satoh K, Hibi G, Yamamoto Y, Urano M, Kuroda M, Nakamura S: Follicular dendritic cell tumor in the oro-pharyngeal region: report of a case and a review of the literature. Oral Oncol 2003, 39:4I5-4I9.

14. Gabizon A, Shmeeda H, Barenholz Y: Pharmacokinetics of pegylated liposomal Doxorubicin: review of animal and human studies. Clin Pharmacokinet 2003, 42:419-36.

15. Cattel L, Ceruti M, Dosio F: From conventional to stealth liposomes: a new frontier in cancer chemotherapy. Tumori 2003 , 89:237-49.

16. Sharpe M, Easthope SE, Keating GM, Lamb HM: Polyethylene glycol-liposomal doxorubicin: a review of its use in the management of solid and haematological malignancies and AIDS related Kaposi's sarcoma. Drugs 2002, 62:2089-126. 